\title{
Child Welfare Policy and Practice: Rethinking the History of Our Certainties
}

\author{
Rosemary Sarri \\ Janet Finn \\ University of Michigan
}

\begin{abstract}
This paper presents a critical retrospective examination of the policies and practices in child welfare as these relate to the declining well-being of children today. There are four key structures around which child welfare is organized: family, state, market and charity. The development of child welfare practices over time follows a cyclical process modulated by the power relations among these key structures that has favored systemic maintenance over transformational change. It is suggested that child welfare policy and practice is informed by three "certainties" or accepted truths that are embedded in broader cultural understandings and that come to be seen as constants rather than as variables. The certainties we address here are: the dichotomy of public and private; the primacy of autonomous individualism and the capacity of corrective intervention. Acting on these certainties not only limits the scope of problem solving in child welfare, but more fundamentally, it constrains the formulation of critical questions about the nature of child welfare policy and practice. The future of practice must explore a new set of critical questions that challenge these certainties if truly empowering models of child welfare practice are to be developed.
\end{abstract}

The well-being of children is an issue of critical concern both in the United States and throughout the world. Racism, violence, poverty, and homelessness shape the early life experiences of millions of children and youth. Grass roots activitists and child welfare advocates have worked tirelessly to place the concerns of children and youth on the public agenda in both national and international arenas. Major changes are underway in some countries to create new frameworks for considering the care and

This research was supported in part by a Senior Faculty Award from the Lois and Samuel Silberman Fund to whom we express our appreciation for that support. We also wish to thank our many colleagues for their reviews, comments and suggestions on this paper.

Requests for reprints should be sent to Rosemary Sarri, School of Social Work, University of Michigan, 1065 Frieze Building, Ann Arbor, MI 48109-1285. 
upbringing of children in contemporary post-industrial society. Numerous proposals are forthcoming for policies, programs and intervention technologies. However, few of these proposals challenge the basic elements of the child welfare system as it has been in place throughout this century. A systematic analysis is necessary to come to terms with our history of fragmented, ad hoc, reactive interventions by policy makers, practitioners, and social scientists that have produced little fundamental reform.

Ivan Illich (1990), in a forceful commentary on ideologies of helping and rehabilitation, challenged the "history of our certainties" those truths that go unquestioned while serving as powerful guides to the development of policies and practice. By certainties we refer to the representations and assumptions that are intimately embedded in an individual's cultural world view, renewed through social practices, and reinforced by social institutions. Through these mutually supporting processes some fundamental certainties come to be widely shared in particular social and historic contexts. They "go without saying" and come to be perceived as constants that persist in the face of social practices that contradict their truth value. Certainties both shape and are reinforced by social structures and practices, becoming a part of a broader cultural script in such a way that they are not challenged in the construction of social problems nor in the process of problem resolution.

This paper will examine three certainties that inform the field of child welfare: the dichotomy of private and public domains; the primacy of autonomous individualism; and the capacity for corrective intervention. These certainties are historically embedded in the structures and practices of the child welfare system. They shape the practitioner's and policy maker's perceptions of the children and families the system serves. Despite a long history of reform, these certainties have remained entrenched. By challenging these certainties we may free our thinking to explore new understandings of child well being.

The certainties selected here frame the ways in which information regarding child well being is rendered meaningful. They persist in the face of fluid and contradictory social practice and thereby help to shape the social constructions of deviance and dependence. These certainties are reinforced through the structure and function of our legal and educational systems, and through informal socialization processes. First, the dichotomy of public and private is a structural certainty which defines boundaries and ascribes role expectations in the child welfare system. Second, the certainty of autonomous individualism delimits our social construction of actors, with implications for practice and relations to structure. Third, the capacity of corrective intervention is a certainty of practice that embodies beliefs about the nature of "doing good." It masks the often 
coercive nature of child welfare practice. These three certainties are interconnected and mutually reinforcing. They have become encoded in the language of professionalism. This exclusive language defines the boundaries of the worker-client relationship and limits the audience in which knowledge is shared. We will consider each by building a case for its status as a certainty, bringing evidence to bear that challenges its truth value, and illustrating the ways it has historically informed child welfare policy and practice.

\section{Critical Institutions}

Four critical institutions within which these certainties have evolved are key to understanding the field of child welfare: state, family, charity and market. The state has been defined as the formal public system of statutes, policies, and agencies with legal responsibility for children. The family has historically been viewed as the primary institution responsible for children's welfare. Both statutory law and beliefs about tradition operate to enforce familial responsibility for sustenance needs, education and general socialization of children. Charity has included churches and voluntary organizations that provide social services and social supports for children. The market has described the private sector organizations that provide services for fees, such as private-for-profit organizations, as well as organizations who receive contracts from the state to provide services. The market, more generally, refers to the labor market, whose productive and reproductive interests are intimately tied to family life. The relations among these four institutions define the terrain in which child welfare policy and practice is carried out.

We envision family, state, market and charity as intimately linked, and constructed in relation to one another. The relative power of each varies in the interaction as relations are renewed or renegotiated through the language and practice of care and control. The concepts of care and control are central to the relations among these institutions and to the construction of child welfare as a field of public concern. These relations legitimize institutional autonomy, provide for a system of checks and balances, promote investment in both social and physical structures and preserve the structural status quo. The structural base thus established constitutes a constraining framework for actors and actions. It is within this arena that child welfare policy is constructed, implemented and modified, and within which the certainties operate.

The Certainty of Structure: The Dichotomy of Public and Private Domains

The certainty of the natural and necessary separation of public and private domains has a long history. This dichotomy was articulated by 
Aristotle who defined the public as the realm of the political where men participated as full citizens (Elshtain, 1982). In this dichotomy, the public domain was constructed as the domain of government, labor and decision making, while the family and the home constituted the private domain. Historically, the dichotomy of public and private domains has been expressed in alternative forms that variably crosscut the terrains of state, family, market and charity. The emphasis on separation of church and state is premised on this dichotomy as is the folk theory of the free market economy that represents government as the neutral regulator of social relations with a laissez-faire relationship to the market.

This dichotomy is problematic and has been subject to challenge. It poses notions of individual rights against those of public interest. Katz (1986) has challenged this dichotomy and the conception of the state as protector of a homogeneous public interest upon which it is based. In this dichotomy, the family is represented as a private, single interest entity separate from the public domain. Gordon (1985) has argued against this assumption, and drawn attention to both intra- and extra-familial power relations. Further, in relation to child welfare, we suggest that this certainty serves to sanctify the privacy of the family and polarize the sanctity of the family and the best interests of the child. This polarity assumes the inherent value of the family's right to non-interference and the child's right to treatment. By drawing the line of debate along this axis, questions about the family's right to social support, the intra- and extra-familial relations of power, and the coercive aspects of treatment are not addressed. While non-interference in the family characterized the approach to middle class families, the opposite was often expressed toward working class and single parent families. The latter families have experienced frequent coercive intervention and control in the name of child welfare.

Janet Finch describes the state's commitment to supporting the family as a "curious mixture of the benign and the sinister" (Finch, 1989, p. 115). The public scrutiny and moralism that accompanies public assistance to single mothers with children illustrates this mix. Coercive state intervention under the guise of child protection imposed upon these women would not be tolerated in middle-class two-parent families. Single mothers are treated as commodities to be shaped by state intervention; if women do not respond appropriately, children are coercively removed. Professionals often fail to realize that people's functioning as parents and the care that they are able to provide, is profoundly influenced by actions of the state.

We have argued that the assumption of the public's right to intervene in the privacy of the family for the best interest of the child is premised on this certainty of structure. As Rothman has pointed out (1980), there has been a commonly held belief that the best interests of the child and state 
were one in the same. Rather than challenging this belief, child welfare advocates have historically focused their debates on the relative merit of public versus private auspices for the care and control of children. For example, children's asylums were touted as a private response to the care of children that offered a better alternative than the deplorable conditions of the public almshouses. However, these early private institutions were often supported in part by public funds. It is interesting to note that blended funding arrangements have historically been the norm, thus blurring the boundaries between what constitutes "public" and "private." By framing the debate around who pays and the relative merit of public and private services, critical questions about which children are judged in need of placement and what conditions contribute to that need are not addressed.

The philosophy of parens patriae that has historically guided the juvenile court system provides an intriguing example of the power of this certainty in shaping policy and practice. It is premised on several assumptions: that the best interests of the youth overrides the family's right to privacy; that the family has failed in its private efforts; and that public intervention is both necessary and positive. The state, acting in place of the father, intervenes as the benevolent administrator of loving justice (Rothman, 1980; Sutton, 1988). In this nexus of public and private patriarchies it is assumed that the state is upholding the best interests of the youth. However, this paternal power of the state has been unevenly applied to families and youth with fewer political and economic resources. Reform efforts in juvenile justice have challenged both the legality and the presumed neutrality of this level of state discretion.

Perhaps the development of the public education system represents one of the more sweeping penetrations of the ostensibly separate domains of the public and the private as schools have taken over a major role in the socialization of children. The public education system was initially envisioned as a powerful means for democratizing society. That goal, however, has been displaced. Apple (1982) argues that public education has become a crucial mechanism for differential socialization of children for their places in a stratified labor market. In effect, the school became a state-funded arm of the labor market, and in recent years it has drifted toward becoming an institution for custodial control of children and youth. Renewed emphasis on enhancing education today provides an opportunity for transforming this critical institution.

The history of the education experience Native American children poses a particular contradiction to the dichotomy of public and private and illustrates the blurring of boundaries among family, state, church and labor market. The "civilizing mission" that shaped 19 th and early 20 th century federal policy toward Native Americans formalized a powerful partnership 
between church and state. Through the boarding school system, thousands of Native American children were separated from their families, communities and cultures; social control was imposed in the name of education. Further, appropriation of Indian child labor became an institutionalized part of the education process. Native American youth provided the labor to maintain the institutions in which they were placed; through the "outing system" they exchanged their labor for the "privilege of placement with a white family; and in some instances, they became a low wage labor pool in the communities that hosted Indian boarding schools. (Adams, 1988; Holm, 1979; Trennert, 1988).

This certainty, the dichotomy of public and private domains, is deeply embedded in American life as we have shown (Steiner, 1976). Today, more than ever, there is a renewal of commitment toward privatization with respect to intervention but far less acknowledgement of the family's right to privacy with respect to children, except for their responsibility for control and financial support. Policy and practice in child welfare are built upon this certainty, but there is little explicit awareness of the contradictions involved. Lastly, our discussion indicates that other critical issues in child welfare are masked by the focus on juxtaposing rights of privacy against those of the public interest.

\section{The Certainty of Actor: The Primacy of Autonomous Individualism}

The primacy of the autonomous individual is deeply embedded in Western cultural scripts (Bellah, Madsen, Sullivan, Swidler, \& Tipton, 1985). This social construction was reflected in and institutionalized through the U.S. Constitution which is premised on the value of individual liberties and rights of citizens. The certainty of the autonomous individual polarizes the concept of dependence and independence and delegitimizes the notion of interdependence. It is implicit in religious ideologies premised on beliefs in individual sin and salvation. Ironically, behind the primacy of individualism there is a powerful ethic of conformity. Cultural understandings and practices related to children, family and community that differ from the dominating values in a given historical context have been labeled as deviant. However, one's capacity to "conform" is powerfully affected by access to rights and resources.

These failures to conform earn the label of deviance or pathology which justifies more repressive forms of social control. Coercive control is disproportionately imposed on members of minority groups and the poor. The history of practice in schools and children's institutions has been one of rigid discipline suggesting the value of control over caring. The well disciplined, individual student is socialized to become the welldisciplined individual worker. While schools recognize the achievements 
and deficits of individual students, children's institutions have focused on the pathology or delinquency of the individual child. More recently, attention has been focused on "dysfunctional families," broadening the scope of pathology, while still emphasizing the location of pathology within the individual family member rather than in political economic structures or relations.

This certainty is encoded in and reinforced by our judicial system which protects the rights and punishes the wrongdoings of the individual as an autonomous actor (Turkel, 1988). It is implicit as well in the medical model that emphasizes the individual as the source of problem and target of treatment. Through acceptance of this certainty we create a base for a personal deficiency model of deviancy and pathology. The celebration of the autonomous individual veils the power relations at work in the construction of individuality (Foucault, in Dreyfus \& Rabinow, 1983).

One's status as an individual is affirmed through the rights and limits of citizenship. Those who have been labeled dependent or deviant are not viewed as full citizens with equal rights to social participation. In this perspective, children are, by nature, dependent, not having achieved the status of full personhood. If families fail to meet the dependency needs of children, through participation in a limited range of socially sanctioned child rearing practices, they are viewed as deviant (Friedson, 1965). This status has been legally legitimated in several states through laws which provide penalties and controls for "Families in Need of Supervision" or FINS as they are often referred to (Levin \& Sarri, 1974).

Current discourse in child welfare emphasizes the value of individualized treatment planning. Behind this recognition of individuality rest assumptions about conformity and the necessity of individual adaptation to existing social expectations that reflect the dominant values of white and male middle- class society. These practices serve to blind practitioners to questions of gender, race and class inequity and cultural differences as they affect their clients and their own social positions.

This certainty has implications for our conceptualization of childhood. Children have been historically been viewed and valued as chattel, economic resources, and objects of affection and sentimentality (Zelizer, 1985). None of these perspectives capture the phenomenon of childhood nor do they recognize children as engaged participants actively constructing meaning in their worlds. Children are seldom if ever viewed in terms of their own personhood, and thus, little concern is expressed about their inherent rights. Children tend to be viewed as apolitical (Coles, 1986); by ignoring the political life of children in child welfare policy and practice, we fail to recognize the differential impact of institutional power relations on the experiences of childhood. 
Lyons (1983) argues that individual autonomy is not self-evident. She asserts that there are two distinct modes of describing self in relation to others: the separate- objective mode presumes that relationships are experienced in terms of reciprocity, mediated through rules and grounded in roles; the connected self presumes that relationships are experienced as response to others on their own terms, mediated through the activity of care and grounded in interdependence. Gordon (1985) points to the need to acknowledge a broader level of social commitment that demands a move from an individual rights model to a vulnerability model of social responsibility. Despite these challenges to the certainty of autonomous individualism, there is a strong investment in the maintenance of its truth value (Bellah, et. al., 1985).

\section{The Certainty of Practice: The Capacity for Corrective Intervention}

Care and control constitute society's primary mandate to the child welfare system. We consider "caring" to be those actions directed toward supporting and promoting well being in a context of affective attachment (Graham, 1983). Control practices are those that limit and constrain one's actions, including both socialization toward self discipline as well as varying degrees of external coercion. Care and control are not mutually exclusive. In fact, they co-exist in most child welfare programs. The practices of care and control are informed by the certainty of our capacity for corrective intervention. Moral prescripts about "doing good", a positivist philosophy of social change, the "can do" attitude of American entrepreneurship, and rapid technological development, have converged in sanctifying the truth value of this certainty. The elaboration of scientific knowledge bases and the development of new technologies has reinforced the belief that we have both the capacity and resources to help.

The certainty of corrective intervention is embedded in a cultural script that also includes the certainties of autonomous individualism and the dichotomy of public and private. Thus our beliefs about doing good are compatible with an understanding of correction that focuses on individual pathology and remediation. The longstanding prominence of the medical model in juvenile justice, child abuse, neglect and dependency, and mental health is illustrative of the power of this certainty (Tuma, 1989; Wilson \& Hernstein, 1986, p. 226).

The juvenile justice and child welfare systems are the key conduits for the placement of youth in "out-of-home care," a term that masks the coercive aspects of child removal. Recent evidence indicates that this discretionary power of the state has expanded to the market and charity through the elaboration of practices that promote the confinement of youth in a broad range of institutions (Lerman, 1990; Weithorn, 1988). Increased discretionary authority has often resulted in greater intrusion into less 
powerful families, often with very negative outcomes for child well-being (Pelton, 1989; Sutton, 1988; U.S. House of Representatives, 1989). With an expanding service economy, the profit potential in "caring" services is a growing concern and poses a challenge to the distinction of profit motive and altruism. The proliferation in recent years of for-profit psychiatric and chemical dependency facilities exemplifies the encroachment of the market into the ostensibly "private" domain of the family that has already been claimed by charity and the state.

Our notions of helping have come to be represented by a commitment to professionalism, specialization and the value of personal change. The elaboration of diagnostic techniques, labels and intervention strategies has broadened the catchment area for control of deviance under the guise of care and treatment. This elaboration has necessitated an expansion of the service economy as well, but that expansion has emphasized only interpersonal change technologies and occasionally education, not the provision of economic and social resources needed by families with children. The examples we have put forth in outlining the certainties of structure and actor also speak to the enduring belief in the capacity for and right to treatment. The right to treatment locates both problem and intervention at the individual level. Even when the professional rhetoric has condemned the political and economic conditions which reinforce problematic social relations, the convergence of our certainties promotes attention to intervention in the discrete and specific symptoms manifest at the individual level.

The certainty of corrective intervention assumes that treatment is not only individual and helpful but also politically neutral. The individual, professionally-neutral focus masks the personal and political pain of racism, classism and sexism that is maintained through these patterns of practice. For example, the literature on childhood psychiatric disorders suggests the over-representation of black youth among those diagnosed as suffering from "conduct disorder" (Gibbs, 1988; Hogan \& Siu, 1988; McAdoo, 1989). The children of low income, single-parent female-headed households are significantly over represented among those labeled "seriously emotionally disturbed" (Knitzer, 1982; McLoyd, 1990; Tuma, 1989). Historically, "sexual promiscuity" has been a primary indicator of pathology in adolescent females, though not identified as a problem when similar behavior is evidenced by males (Sarri, 1980). A recent provocative analysis by Kamin (1990) of Sheldon's criminal trait studies of the 1940s has uncovered the blatant racism that has informed supposedly "scientific" theory of the nature of deviant personality. By focusing on the pathology of the individual, patterns of repression that exacerbate personal stress have been masked and reinforced (Barclay-McLaughlin, 1990). 
In addressing the certainty of our capacity for corrective intervention, it is necessary to explore the gendered nature of care and control practices that underlie this truth (Graham, 1983). The language of caring depicts personal, informal and emotional qualities, traditionally ascribed to women and the private domain. The language of control is that of the objective, rational and impersonal, ascribed to men and the public domain. Ironically, these gendered images have been appropriated in ways such that the language of nurture, care and support veils coercive practices of control. Consider the current interest in a continuum of care in child welfare services. The activities of nurturing and tending, those often repetitious daily support activities, tend to be conceptualized in policy and practice as "women's work". As such they are of the private, informal domain and are given little value in the market. In contrast, as one moves along this continuum, the practices of "caring" become more intrusive, restrictive, and costly.

\section{The Historic Perspective}

The history of child welfare provides the context within which the interaction between structure, practice and actors unfolds. Through a critical look at child welfare history we come to question the sense of continuity that has masked the conflicts, violence and coercion that have been carried out in the name of welfare (Gil, 1985). We need to address the experiences of the poor, immigrants, and people of color and explore the differential impact that child welfare policies and practices have had on those with limited access to rights and resources. Through the lenses of history we can gain a perspective on current concerns and future directions in child welfare. We can be better prepared to raise questions about the certainties that limit contemporary cultural scripts. In this paper we are self-consciously selective in our use of history, offering brief sketches that emphasize a circumscribed set of structures and practices. We do not propose to present an exhaustive historical analysis; rather we offer a historic context from which to consider the persistence of certainties over time in ways that have limited the questions asked and the answers posed in the field of child welfare.

Early child welfare practices were tied to fears of social chaos and the need to instill order and discipline in the "dangerous classes" (Brace, 1872; Bremner, 1970). As early as 1834 social reformers were describing the over representation of black youth among delinquent populations of the nation's growing urban centers (Hart, 1834, in Bremner, 1970). While the cause was attributed to severe economic deprivation suffered by the black community, the proposed solution called for construction of segregated institutions to confine these youth. Similar patterns of discrimination 
existed toward females who were often institutionalized for behavior that was not defined as troublesome for males. For young women, their "danger" to society has been, and continues to be, constructed in terms of their sexuality. Poor immigrant children were the targets of Charles Loring Brace's plan for "moral disinfection" of the cities through foster placements with rural families in the West (Brace, 1872). Brace was accorded broad discretionary power and assumed the role of the social control arm of the state (Costin, 1985). The dilemmas between care and control, as well as the influence of religious ideologies, are evident from the practices of the Houses of Refuge, the children's asylums, and the emerging foster care system (Costin, 1985; Sutton, 1988, 1990). Charity was a dominant force, but one that often was linked to the market as children were trained and then provided as docile workers for employers.

At the turn of the twentieth century, amidst a flurry of reform, advocates declared this the "Century of the Child". Child well-being became the subject of national conferences and the field of child welfare began to professionalize. The creation of the Juvenile Court heralded a new stage where the state formally entered into decision making that profoundly affected families and children through the operationalization of parens patriae (Levin \& Sarri, 1974). This period also saw the emergence of leaders in social welfare who advocated for the well being of urban children through support of child labor laws, public health measures, the development of probation, and support for the extension of public education. But, as Ehrenreich (1987) and Platt (1964) observe, these reforms also served social control purposes, especially in their impact on immigrant populations. The early 20th century also saw the emergence of scientific charity, social diagnosis, and expansion of professional services informed by an ideology of efficiency.

The progressive era ushered in the rhetoric of family preservation and support of outdoor relief as an alternative to institutional care, at least for the children of the "worthy" poor (Abramowitz, 1988). In spite of the rhetoric, out of home placement rates continued to rise. The institutional placement patterns of the early 1900's suggest a focus of social control on children of color. Early reports of children in out-of-home placement indicated that black youth were significantly over represented in institutions, along with immigrant children (Bureau of the Census, 1927, 1935; Lerman, 1990). And as we have noted, for Native American children, boarding schools were the dominant institutional form of social control.

In the 1930's the Federal government assumed responsibility for a variety of income maintenance programs, including those for dependent children. In addition, numerous social service programs were instituted to serve educational and employment needs of youth believed to be at risk for delinquency. The early programs helped to shape a concept of "youth-at- 
risk" which remains central to current policy and practice. Many of these programs were Federal grants-in-aid that implicated the states in new public responsibility for children and families. They permitted broad state discretion that is still with us today, shaping the contested terrain of child welfare.

The decade of the 1960's heralded another period of extensive development of child welfare policy and programs. The changes were widespread ranging from increased concern with children's rights and civil liberties to deinstitutionalization. Preventive efforts in juvenile delinquency emphasized youth development and community social action over coercive control. The amendments to the Social Security Act of 1962 significantly expanded the services of the child welfare system. Large numbers of social workers were trained for the child welfare system, but most of that training emphasized professionalism, specialization and maintenance of the traditional structure and practices. Once again the certainties were reinforced. With the proliferation of training and services came a renewed interest in the technologies of individual diagnosis and treatment. As Pelton (1989) points out, at the very moment that the differential impact of child welfare practices on the poor were being questioned, the medical model approach of $\mathrm{C}$. Henry Kempe, articulated as the "battered child syndrome," captured the attention of child welfare advocates and diverted attention from structural issues of poverty, sexism and racism.

The 1980's saw a return to more punitive policies and practices affecting children. Federal cutbacks placed greater burdens on state and local governments and especially on charity, often resulting in loss of benefits and services to those most in need. As was the case 150 years ago, children of color are over represented in the more coercive institutions. This is epitomized in the current plight of young black males, characterized by a one in four incarceration rate and severe economic and educational disenfranchisement (Edelman, 1987; Gibbs, 1988). This must be seen as a culmination of a long history of structural power imbalances that have shaped child welfare policy and practice. As of 1990, the majority of children in the child welfare system are from oppressed minority groups (U.S. House of Representatives, 1989). Moreover, the total numbers of all children in placement continues to rise to the highest rates in history. Poor children continue to be significantly over represented among those identified as delinquent, abused or neglected. Yet the professional discourse continues to emphasize the classlessness of child abuse and neglect. As child abuse has gained recognition as a serious social problem, there has been a rapid expansion in technologies of diagnosis and intervention. Child welfare workers, motivated by an ethic of care, find themselves instead overwhelmed and overburdened in systems driven by concerns for liability and social control. 
Child protective services have evolved to a highly specialized form of intervention incorporating a blend of care and control that is part SWAT team and part MASH unit. Child protective services dominate the child welfare system (Kammerman \& Kahn, 1990). The caring tasks of tending and support have been eclipsed by demands for prosecution, treatment, accountability and social control. In 1990, as in 1830, the children impacted by the child welfare system are disproportionately from poor and single parent households (Edelman, 1987). They have been categorically distinguished, emphasizing their individual problems and de-emphasizing their common struggle. The long term effect has been one of systemic neglect and coercive control of a significant proportion of children and families. While the language of family preservation remains strong, the patterns of practice continue to emphasize removal of children to foster care, residential treatment, and hospitals, resulting in the growing transinstitutionalization of youth (Weithom, 1988).

\section{Conclusion}

We have described and discussed the three certainties that appear to have been critical to the development of child welfare structures, practice and actors, and have illustrated their continuing presence at several key points in the past century and a half. The task facing us now is to develop a critical curiosity that would challenge these certainties (Bruss \& Macedo, 1990). Only then will one be able to propose empirically verifiable propositions. It is also desirable to link research, social work education and practice as necessary prerequisites for creating the dynamic tensions that mitigate against the petrification of beliefs into immutable certainties. The current applications of intensive family treatment services to reduce or prevent out-of-home placement are unlikely to succeed unless these programs address the major causal factors driving placement: poverty, unemployment, poor housing or the lack of basic services such as parental leave and child care.

All too often existing strategies for reform are based on improved bureaucratic functioning, more specialization, coordination and professionalization. These approaches fail to appreciate the cyclical nature of social reform. Today one hears proposals for reestablishment of orphanages by those who apparently have not examined the history of children's experiences in these institutions (Ladner, 1989; Rothman, 1980). Agencies are willing to allocate most of their resources to placement rather than prevention and family resource development. When we are willing to pay 100 times more for residential care than we will provide to a child receiving AFDC, it is not surprising that placement patterns are what they 
are. Social workers perform dual roles as caregiver and control agents for the state with the result that the latter generally becomes the dominant force nearly always. Yet, we fail to develop the leadership and advocacy necessary to transform the system because we limit the questions asked and accept the certainties that have informed child welfare practice. As a result these approaches effectively truncate efforts of personal and political empowerment, even when they utilize the language of empowerment as a goal(Solomon, 1990).

Pelton (1989) as well as Piven and Cloward (1971) contend that rapid expansion of social services occur at moments of intense pressure for more fundamental change. It is argued that at times of increased turbulence and demands for reform there is an expansion of services intended to relieve pressure while preserving the structural status quo. Our analysis suggests that the history of child welfare is characterized by cycles of reactive response in which key themes are repeatedly articulated as the tensions of care and control are played out. These themes reinforce and are reinforced by the certainties that inform them.

This process of intervention and response is not just a repetitive cycle, but rather this process can best be conceived of as an ever-expanding spiral. Through the process of repetition and elaboration the child welfare system has grown ever more complex and fragmented. The certainties inform a response pattern of reaction to the interventions of the previous generation. But, the actual practices grow increasingly more complex as they are layered on preexisting policies, attached to existing programs or mapped onto strongly held ideologies.

While these patterns of history are troubling, they also offer insights for the future. We need to recognize the interconnectedness of social structures; examine the relations among the structures; and ask how the notion of separate spheres systematically reinforces particular patterns of practice and limits the actions of certain groups. We need to challenge ourselves to look beyond autonomous individualism to relational selves and collective responsibility. Reducing harm and the provision of social caring should be primary goals rather than rehabilitation control and punishment. We need to examine the power relations implicit in models of treatment that privilege expert authority over collective knowledge for social action. By understanding the cyclic nature of our rhetoric and the spiralling expansion of our practices we can begin to challenge the underlying certainties and explore strategic avenues for empowering interventions.

Finally, we need to learn important lessons about the phenomenon of childhood. It is critical that we come to appreciate that which we no longer experience, that which we have sacrificed through acceptance of our certainties. Throughout the history of child welfare policy we have muted that which is childlike. Children experience themselves as em- 
bedded in the center of their worlds, with a "bottom-up" view of that embeddedness. Perhaps we can recapture an appreciation of a configurational approach to relationships, the value of differentiation in a context of attachment, and the essence of interdependence and vulnerability. We may also come to appreciate the sense of urgency that dominates a child's understanding of time and the devastation wrought by lingering indeterminate placements away from family and community, with little or no sense of belonging to anyone.

Societal co-responsibility with parents for children's well-being must be acknowledged, especially in the case of poor and/or single parents families who cannot alone perform all the necessary parental functions (Edelman, 1987). This would entail the provision of concrete specific services to the parents in collaborative-cooperative relationships. Reduction of the numbers of children in substitute care as well as the length in care is likely only where there is empowerment of parents, as is now provided for in the Children's Act of 1989 in Britain. Family preservation programs which are now operative in many states also represent a significant effort to work with families so that they will be empowered to function effectively as parents. These programs also require interdependence with charitable organizations on the part of the state and family.

The development of caring communities that are empowered to address successfully the problems of their children will not be easy, nor will it be accomplished quickly. Nonetheless, such an approach appears to offer the greatest potential for success. In turn, vital communities will be ones in which families are supported and encouraged in carrying out their roles in child rearing and socialization. This is the challenge for social work if it is to play a role in transforming child welfare.

\section{References}

Abramowitz, M. (1988). Regulating the lives of women. Boston: South End Press.

Adams, D. (1988). Fundamental considerations: The deep meaning of Native American schooling, 1880-1900. Harvard Educational Review, 58, 1-28.

Apple, M. (1982). Education and power. Boston: Routledge \& Kegan Paul.

Barclay-McLaughlin, G. (1990). The limitations of the parent-child interaction model for early intervention programs in poor urban settings. Unpublished manuscript. Ann Arbor: University of Michigan.

Bellah, R., Madsen, R., Sullivan, W., Swidler, A., \& Tipton, S. (1985). Habits of the heart. New York: Harper.

Brace, C. (1872). The dangerous classes of New York and twenty years work among them. New York: Wynkoop \& Hallenbeck. 
Bremner, R. (Ed.) (1970). Children and youth in America: A documentary history, Vols. I-III. Cambridge: Harvard University Press.

Bruss, N., \& Macedo, D.P. (1990). Toward a pedagogy of the question: Conversations with Paolo Friere. Journal of Progressive Human Resources, 1 , 9-12.

Bureau of the Census. (1927). Children under institutional care, 1923. Washington DC: U.S. Government Printing Office.

Bureau of the Census. (1935). Children under institutional care and in foster homes, 1933. Washington DC: U.S. Government Printing Office.

Bureau of the Census. (1988). Children in custody. Washington, D.C.: U.S. Government Printing Office.

Coles, R. (1986). The political life of children. Boston: The Atlantic Monthly Press.

Costin, L. (1985). The historical context of child welfare. In J. Laird \& A. Hartman (Eds.), A handbook of child welfare (pp.34-60). New York: Free Press.

Dreyfus, H.,\& Rabinow, P. (1983). Michel Foucault: Beyond structuralism and hermeneutics. Chicago: University of Chicago Press.

Edelman, M. (1987). Families in peril: An agenda for social change. Cambridge: Harvard University Press.

Ehrenreich, J. (1987). The altruistic imagination. Ithaca, NY: Cornell University Press.

Elshtain, J. (Ed.). (1982). The family in political thought. Amherst: University of Massachusetts Press.

Finch, J. (1989). Family responsibility and social change. Cambridge: Polity Press.

Friedson, E. (1965). Disability as social deviance. In M. Sussman (Ed.), Sociology and rehabilitation (pp. 71-99). Washington, D.C.: American Sociological Association.

Gibbs, J. (1988). Young black and male in America: An endangered species. Dover, MA: Auburn House Publishing.

Gil, D. (1985). The ideological context of child welfare. In J. Laird \& A. Hartman (Eds.). A handbook of child welfare context, knowledge and practice (pp. 11-33). New York: Free Press.

Gordon, L. (1985). Child abuse, gender, and the myth of family independence: A historical critique. Child Welfare, 64, 213-224.

Graham, H. (1983). Caring: A labour of love. In J. Finch \& D. Groves, A labour of love: Women, work and caring (pp. 3-27). London: Routledge and Kegan Paul.

Hart, N. (1970). Correspondence to S. Allen, Allen Papers, 1834, New York Historical Society. In R. Bremner (Ed.) Children and youth in America: A documentary history, Vol. 1. Cambridge: Harvard University Press, pp. 687688. 
Hogan, P. \& Siu, S. (1988). Minority children and the child welfare system: a historical perspective. Social Work, 33, 493-499.

Holm, T. (1979). Racial stereotypes and government policies regarding the education of Native Americans, 1879-1920, Multicultural Education and the American Indian. Los Angeles: The University of California, American Indian Studies Center.

Illich, I. (1990). Reaffirming rehabilitation II. Conference address, National Center on Institutions and Alternatives, Arlington, VA.

Kamerman, S. \& Kahn A. (1990). Social services for children, youth and families in the United States. Children and Youth Services Review, 12, 1-185.

Kamin, L. (1990). Reaffirming rehabilitation II, Conference address, National Center on Institutions and Alternatives, Arlington, VA.

Katz, M. (1986). A social history of welfare in America. In the shadow of the poorhouse. New York: Basic Books.

Kimmich, M. (1985). America's children, who cares? Growing needs and declining assistance in the Reagan era. Washington, D.C.: Urban Institute.

Knitzer, J. (1982). Unclaimed children: The failure of public responsibility to children and adolescents in need of mental health services. Washington DC: The Children's Defense Fund.

Ladner, J. (1989, October 29). Bring back the orphanages. Washington Post.

Lerman, P. (1990). Counting youth in trouble living away from home: Recent trends and counting problems. New Brunswick, NJ: Rutgers University School of Social Work.

Levin, M. \& Sarri, R. (1974). Juvenile delinquency: A comparative analysis of legal codes in the United States. Ann Arbor, MI: University of Michigan National Assessment of Juvenile Corrections.

Lyons, N. (1983). Two perspectives: On self, relationship and morality. Harvard Educational Review, 53, .

McAdoo, H. (1989). Black families (2nd ed.). Newbury Park, CA: Sage.

McLoyd, V. (1990). The impact of economic hardship on black families and children: Psychological distress, parenting and socioemotional development. Unpublished manuscript, University of Michigan, Ann Arbor, MI.

New York State Senate. (1857). Report of the Select Committee to visit charitable institutions. Doc. 8, Documents (pp. 10-11). Albany, NY. In Bremner, Vol I., p. 663

Ortner, S. (1989). High religion: A cultural and political history of Sherpa Buddhism. Princeton: Princeton University Press.

Pelton, L. (1989). For reasons of poverty: A critical analysis of the public child welfare system in the U.S. New York: Praeger.

Piven, F. \& Cloward, R. (1971). Regulating the poor: The functions of public welfare. New York: Pantheon Books.

Platt, A. (1969). The child savers: The invention of delinquency. Chicago: University of Chicago Press. 
Quinn, N. \& Holland, D. (1987). Culture and cognition. In D. Holland \& N. Quinn (Eds.), Cultural models in language and thought (p. 3-40). New York: Cambridge University Press.

Quinton, D. \& Rutter, M. (1988). Parenting breakdown. Brookfield, VT: Anebury Press.

Rappaport, R. (1979). Ecology, meaning and religion. Richmond, CA: North Atlantic Books.

Rothman, D. (1980). Conscience and convenience: The asylum and its alternatives in progressive America. Boston: Little, Brown \& Co.

Sarri, R. (1980). Adolescent status offender and the juvenile justice system. Children and Youth Services Review, 2, 1-28.

Solomon, B. (1990). Rethinking empowerment. Journal of Progressive Human Services, 1, 27-41.

Steiner, G. (1976). The children's cause. Washington DC: The Brookings Institute.

Sutton, J. (1990). Bureaucrats and entrepreneurs: Institutional responses to deviant children in the United States, 1890-1920s. American Journal of Sociology, 95, $1367-1400$.

Sutton, J. (1988). Stubborn children. Berkeley: University of California Press.

Trennert, R. (1988). The Phoenix Indian School: Forced assimilation in Arizona, 1891-1935. Norman, OK: University Press.

Tuma, J. (1989). Mental health services for children: The state of the art. American Psychologist, 44, 188-99.

Turkel, G. (1988). The public/private distinction: Approaches to the critique of legal ideology. Law and Society Review, 22, 801-823.

U.S. House of Representatives Select Committee on Children, Youth and Families. (1989). Children and families in crises. Washington, D.C.: U.S. Government Printing Office.

Weithorn, L. (1988). Mental hospitalization for troublesome youth. An analysis of skyrocketing admissions rates. Stanford Law Review, 40, 773-838.

Wilson, J. \& Hernstein, R. (1986). Crime and human nature. New York: Macmillan.

Zelizer, V. (1985). Pricing the priceless child: The changing value of children. New York: Basic Books. 